\title{
Cost effectiveness of smart insoles in preventing ulcer recurrence for people in diabetic foot remission
}

\author{
Bijan Najafi ${ }^{1}$, Courtney B Chalifoux ${ }^{2 *}, J_{\text {Breanne Everett }}{ }^{2,3}$, Javad Razjouyan $^{1,4}$, Elizabeth A Brooks ${ }^{5}$ and David G Armstrong ${ }^{6}$ \\ ${ }^{1}$ Baylor College of Medicine, Houston, USA \\ ${ }^{2}$ Orpyx Medical Technologies Inc., Canada, \\ ${ }^{3}$ Section of Plastic Surgery University of Calgary Cumming School of Medicine, Canada \\ ${ }^{4}$ Center for Innovations in Quality, Effectiveness, and Safety (IQuESt), Michael E. DeBakey Veterans Affairs Medical Center, Houston, USA \\ ${ }^{5}$ Decision Driver Analytics Inc., North Carolina, USA \\ ${ }^{6}$ Department of Surgery, University of Southern California, Los Angeles, USA
}

\begin{abstract}
Aims: To show that a device designed to prevent diabetic foot ulcers (DFUs) may help to cost-effectively manage patients at a high-risk of recidivism.

Methods: Decision tree models were used to estimate clinical outcome probabilities and associated costs at three- and 18-months post-DFU closure, comparing standard of care (SOC), or SurroSense $\mathrm{Rx}^{\circledR}$ as an adjunct to SOC. Inputs were derived from a prospective cohort study $(\mathrm{n}=15)$ involving patients with a recent $(<12$ months) history of DFU. This analysis was conducted from the third-party payer perspective with costs presented in 2017 USD.
\end{abstract}

Results: Short-term (three month) results show that care involving the adjunctive use of SurroSense Rx saves approximately US\$978.02 per event avoided (excluding device costs) compared to SOC.

Long-term (18-month) results suggest lower event occurrence rates $(0 \cdot 14$ versus $0 \cdot 62)$, with a cost per ulcer avoided of US $\$ 6,702 \cdot 54$ (versus US $\$ 53,134 \cdot 94$ with SOC alone); this indicates the SurroSense $\mathrm{Rx}+\mathrm{SOC}$ as the dominant strategy.

Conclusions: The results support the cost-effectiveness of smart insoles as an adjunct to diabetic foot care-this could result in substantial savings for the US Health System. More robust studies are required to verify these results, and determine population-level cost savings.

\section{Introduction}

Diabetes-related foot ulcers (DFUs) are a leading cause of hospitalization and amputation worldwide, and account for 33\% of all direct costs of diabetes care in the US [1,2]. Ulcers requiring acute care can result in treatment costs of up to US $\$ 70,000$ per event, varying with the severity of the wound [3]. A major risk factor for DFU is neuropathy-related loss of protective sensation (LOPS) [4,5]. With LOPS, physical trauma, temperature changes and excessive pressure, can cause damage to the feet, thus making patients more susceptible to complications, including tissue breakdown and ulceration, which can ultimately lead to the requirement for surgical amputation [1]. These complications hold the potential to significantly decrease an individual's quality of life and can make it challenging for them to perform everyday activities. It has been reported that individuals with diabetes have a $1-4 \%$ annual risk, and at least a $25 \%$ lifetime risk, of developing a foot ulcer $[1,2,6,7]$. The strongest risk factor for foot ulceration is a history of the same $[2,8,9]$.

At six months post-ulcer healing, ulcer recidivism ranges from 15 to $24 \%$; when expanded to time periods of one year and eighteen months, this increased to 30 to $70 \%$, and 37 to $42 \%$ respectively [2,1018]. There is a notable increase in the costs associated with diabetic peripheral neuropathy (DPN) care when a DFU develops; DFU-related costs increase baseline DPN care 5.4 and $2 \cdot 8$ times in the first and second year post-ulcer treatment, respectively [12]. Given the cost of care, high rates of hospitalization during treatment, and likelihood of recurrence, targeted interventions to limit DFU recidivism show significant promise in managing a growing burden of disease [19]. Recently, we have demonstrated that the use of a novel, interactive insole system (the SurroSense $\mathrm{Rx}^{\oplus}$, Orpyx Medical Technologies Inc., Calgary, Canada), which provides real-time feedback to patients to cue offloading of sustained plantar pressure, is highly acceptable for patients with history of DFU and could assist with improving adherence to protective footwear over time [20].

Figure 1 illustrates the SurroSense $\mathrm{Rx}^{\circ}$ system. It comprises two pressure-sensing inserts and a smartwatch display device. The device alerts the user when "safe" pressure and time thresholds have been exceeded using vibratory and visual feedback. When the wearer receives an alert from the smartwatch, a pressure map of each foot showing the location or locations where sustained pressure is occurring over a period is displayed. The alert thresholds are based on integrating pressure data over time and identifying tissue that is at risk. The person decreases pressure by taking appropriate measures, such as sitting down or adjusting the position of their feet.

In this study, we examined the cost effectiveness of such technology to reduce healthcare costs compared to standard of care (SOC).

Correspondence to: Courtney Chalifoux, Orpyx Medical Technologies Inc., Alberta, Canada, E-mail: courtney.chalifoux@orpyx.com

Received: December 11, 2017; Accepted: December 28, 2017; Published: January 03, 2018 

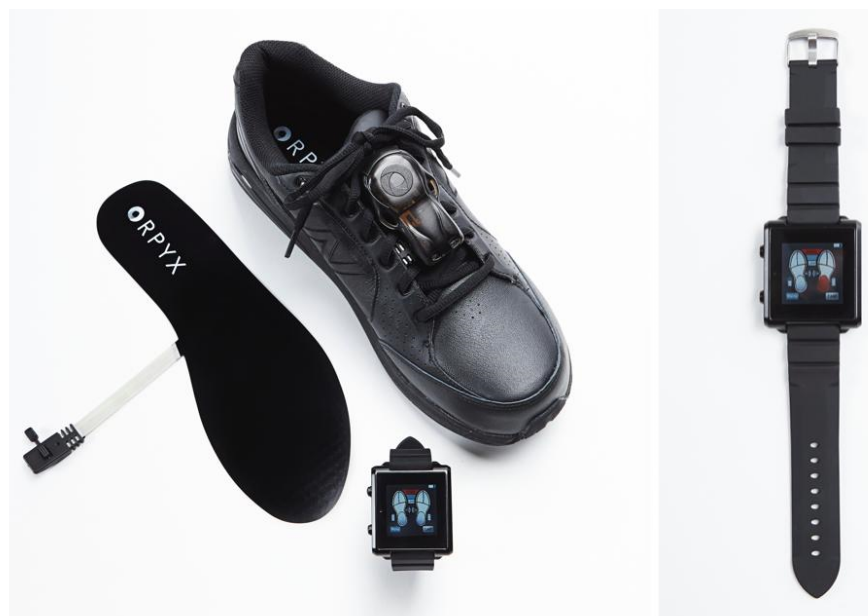

Figure 1. The SurroSense $\mathrm{Rx}^{\circledR}$ Smart Insole System (image permission granted by Orpyx Medical Technologies Inc.)

Specifically, a simulated decision tree economic model was built to explore the short- (Figure 2) and long-term (Figure 3)cost effectiveness of the adjunctive use of the SurroSense $\mathrm{Rx}^{\otimes}$ device in comparison to alone, in the prevention of DFUs with recent history of the same. Device efficacy was estimated using the results of a pilot cohort study that was conducted on patients of the defined demographic. In our analysis, SOC was defined using best practice strategies for the management of patients with a history of diabetic foot disease $[21,22]$.

\section{Research in context}

\section{Evidence before this study}

The background literature review for this study was conducted using PubMed, Google Scholar and Medline. The authors researched North American costs associated with the management and downstream effects of diabetic foot ulcers (DFU), including searches for "hospitalization costs of DFUs", "cost and frequency of DFU dressing changes" and "lower limb amputation costs". Research was examined from 1993 to present with preference given to material that was more current. The analysis focuses on the US healthcare system and because there are no comparable means of preventative treatment on the market, the clinical outcome model inputs were based on SurroSense $\mathrm{Rx}$ usage. One prominent article supports the notion that prevention of diabetic foot ulcers is the most important aspect in tackling diabetic foot disease [2]. Data collected from a previous clinical study using the SurroSense Rx as an adjunct to the SOC illustrated an $83.72 \%$ and $77.42 \%$ reduction in event occurrence over the short and long term respectively; this was analyzed in conjunction with a collection of studies explaining the costs of foot care, wound care and amputation in order to determine cost-effectiveness [20].

\section{Added value of this study}

The primary value of this study is that it supports a previously proposed shift in diabetic foot care that focuses on risk stratification and provision of preventative care to high-risk patients. This approach allocates more substantial resources to the highest risk patients, which enables remission of the most at-risk diabetic feet, thus enabling substantial cost savings. Cost savings to both the patient and the broader health system further demonstrates why the proposed means of reducing DFU recidivism should be considered thoroughly. The adjunctive use of smart wearable medical technologies to SOC in these high-risk patients is not only economically promising, it carries the potential to fundamentally change and improve the current clinical approach to the diabetic foot.

\section{Implications of all the available evidence}

This study illustrates that when used as an adjunct to the current SOC, the SurroSense Rx stands to be a cost-effective means of mitigating DFU recurrence in the US healthcare system. Further investigation of the device in larger randomized controlled trials, and for other highrisk patients (i.e. those with neuropathy and callus-ulcer pre-cursorformation, etc.), is merited.

\section{Methods \\ Model overview}

A cost-effectiveness analysis using two decision tree modelsone at three-months and one at 18-months post-DFU closure-was completed. Both models compared SOC alone, or SOC with adjunctive use of the SurroSense Rx device. The models examined potential clinical outcomes, and their respective costs of care. Clinical outcomerelated inputs to the model were derived from a 2014 pilot cohort study $(n=15)$ completed at the University of Arizona's Southern Arizona Limb Salvage Alliance (SALSA) [20]. Further details of this study are discussed below in "Clinical Outcome-Related Model Inputs." Transition probabilities governing movement through the model are drawn from the best available published or unpublished data, as applicable. As patients progress through the model, cost of event occurrences accrues appropriately. Table 1 illustrates the variables which are represented and manipulated in these models. It also denotes the respective references for each variable and the short- and long-term cost assumptions.

The primary effectiveness measure in each model was the event rate, where an event is defined as the occurrence of either a callus or a DFU. Cost-effectiveness was measured by calculating the incremental cost-effectiveness ratio, defined as the cost per event avoided using the more effective strategy. In addition to the "base case" results using the variable values as noted in Table 1 , a series of one-way sensitivity analyses were performed to determine if the modeled results were robust to plausible ranges of modelled parameters (also noted in Table 1).

Cost data were obtained from the peer-reviewed literature and national average Medicare payment rates, and updated to 2017 USD, where applicable (Table 1). Probability and outcomes data related to use of the SurroSense $\mathrm{Rx}^{\star}$ smart insole system was taken from the SALSA-Orpyx cohort pilot study; methods for this study are outlined in "Clinical Outcome-Related Model Inputs."

Figure 2 provides an abbreviated decision tree at the three-month timepoint for potential outcomes in patients with a history of DFU, based on whether they are assigned to receive SOC only or SOC plus adjunctive use of the SurroSense $\mathrm{Rx}^{\oplus}$ device. Following assignment to one of these care regimens, the patient will then go on to either ulcerate, develop a callus but not ulcerate, or develop neither a callus nor an ulcer within the next three months. Not depicted here, there are multiple potential paths following excursion down one of those six initial paths. For patients who develop an ulcer, they may go on to heal that ulcer, fail to heal that ulcer, develop further ulcers, go on to require surgical amputation, or die. For patients who develop callus, they may remain ulcer free, or go on to develop DFU and persist down any of the aforementioned paths. Similarly, these potential outcome scenarios 


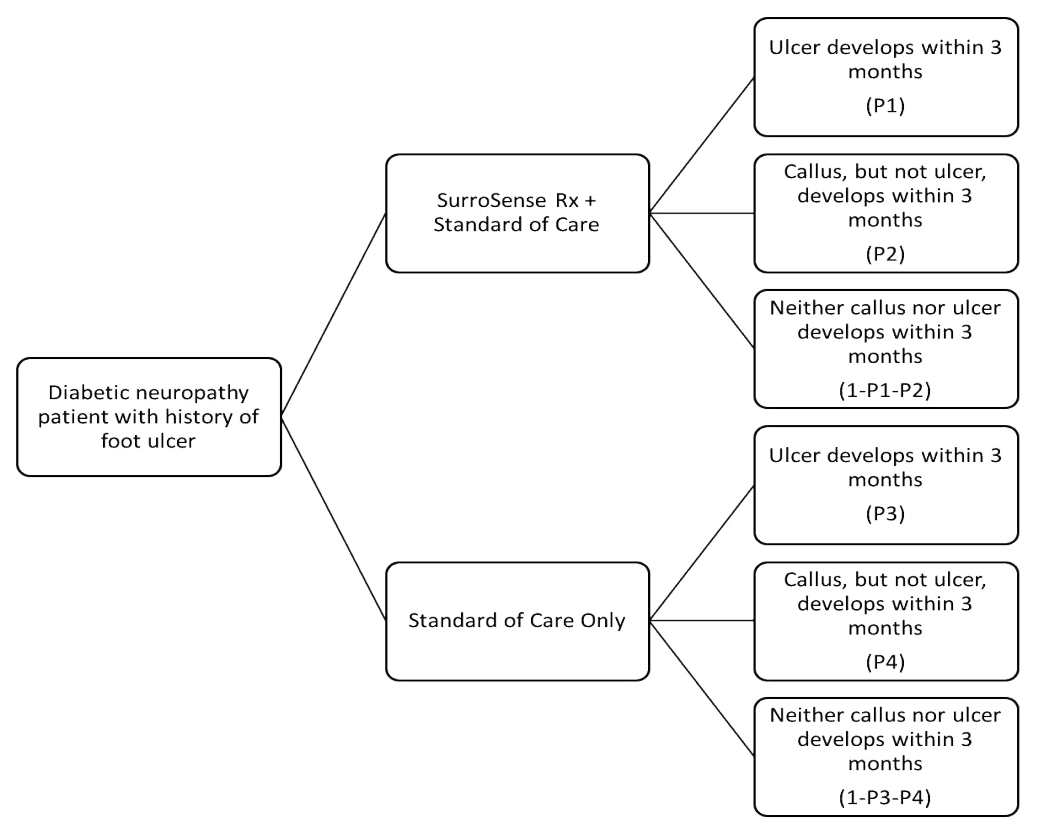

Figure 2. Decision Tree Model Structure: Short-Term Outcomes (3 Months): an abbreviated decision tree for potential outcomes in patients with a history of DFU.

The model begins on the left with assignment to either care involving SOC + SurroSense Rx® or SOC Only. If assigned adjunctive device use and followed for three months, patients will either: a) develop an ulcer, b) develop a callus, or c) develop neither a callus nor an ulcer. The probabilities of these scenarios are P1, P2, and 1-P1-P2, respectively. If assigned to SOC only, the possible outcome paths are the same. Here, respectively, their likelihoods of occurrence are defined as P3, P4, and 1-P3-P4. Based on the SALSA data, probability values are as defined in Table 1.

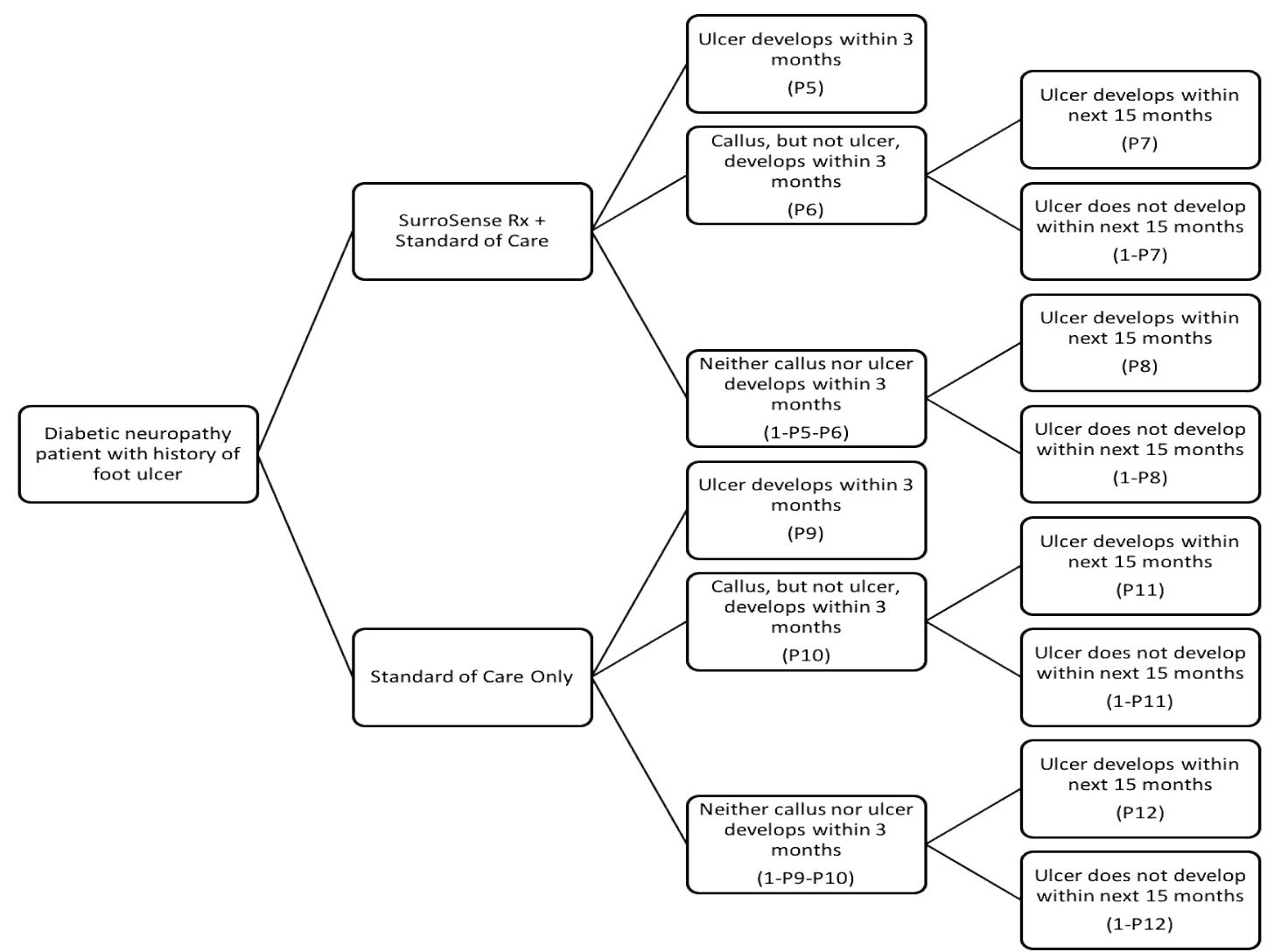

Figure 3. Decision Tree Model Structure: Long-Term Outcomes (18 Months): a decision tree for potential outcomes in patients with a history of DFU.

The model begins on the left with assignment to either care involving SOC + SurroSense $\mathrm{Rx}^{\circledR}$ or SOC Only. If assigned adjunctive device use and followed for three months, patients will either: a) develop an ulcer, b) develop a callus, or c) develop neither a callus nor an ulcer. The probabilities of these scenarios are P5, P6, and 1-P5-P6, respectively. If assigned to SOC only, the possible outcome paths are the same. Here, respectively, their likelihoods of occurrence are defined as P9, P10, and 1-P9-P10. This model further extends potential outcomes of developing an ulcer for a total of 18 months. If patients do not develop an ulcer within the first three months of follow-up, in the next 15 months they will either: a) develop an ulcer after developing a callus, b) not develop an ulcer after developing a callus, c) develop an ulcer after developing neither a callus nor an ulcer, or d) not develop an ulcer after developing neither a callus nor an ulcer. For the group assigned the adjunctive device use, these probabilities are P7, 1-P7, P8 and 1-P8, respectively. The same outcomes apply to the group assigned SOC alone and are represented by P11, 1-P11, P12 and 1-P12, respectively. Based on the SALSA data, probability values are as defined in Table 1 
Table 1. Table of Modelled Variables and Assumptions

\begin{tabular}{|c|c|c|c|}
\hline Variable ID & Variable Description & $\begin{array}{l}\text { Value (Sensitivity Analysis } \\
\text { Range) }\end{array}$ & Reference \\
\hline \multicolumn{4}{|l|}{ Short-Term } \\
\hline SurroSense & $R x \circledR+S O C$ (Active Group) & & \\
\hline $\mathrm{P} 1$ & Likelihood that ulcer develops within 3 months (SurroSense $\mathrm{Rx}^{\circledR}+\mathrm{SOC}$ ) & $0 \cdot 067(0 \cdot 056,0 \cdot 077)$ & $\dagger$ \\
\hline P2 & $\begin{array}{l}\text { Likelihood that callus, but not ulcer, develops within } 3 \text { months(SurroSense } \mathrm{Rx}^{\circledR} \\
+\mathrm{SOC} \text { ) }\end{array}$ & $0(0,0 \cdot 015)$ & $\dagger$ \\
\hline 1-P1-P2 & $\begin{array}{l}\text { Likelihood that neither callus nor ulcer develops within } 3 \text { months(SurroSense } \\
\mathrm{Rx}^{\circledR}+\mathrm{SOC} \text { ) }\end{array}$ & $\begin{array}{l}0.933 \text { (Varies with } \mathrm{P} 1 \text { or } \mathrm{P} 2 ; \text { not } \\
\text { explored separately }\end{array}$ & 0 \\
\hline \multicolumn{4}{|l|}{ SOC Only (Control Group) } \\
\hline P3 & Likelihood that ulcer develops within 3 months (SOC) & $0 \cdot 143(0 \cdot 122,0 \cdot 164)$ & $\dagger$ \\
\hline $\mathrm{P} 4$ & Likelihood that callus, but not ulcer, develops within 3 months (SOC) & $0 \cdot 286(0 \cdot 243,0 \cdot 329)$ & $\dagger$ \\
\hline 1-P3-P4 & Likelihood that neither callus nor ulcer develops within 3 months (SOC) & $\begin{array}{l}0 \cdot 571 \text { (Varies with P3 or P4; not } \\
\text { explored } \\
\text { separately) }\end{array}$ & 0 \\
\hline \multicolumn{4}{|l|}{ Costs } \\
\hline Cost of SOC foot care (per quarter) & US $\$ 132 \cdot 53(\mathrm{US} \$ 112 \cdot 65, \mathrm{US} \$ 152 \cdot 41)$ & [23] & \\
\hline $\begin{array}{l}\text { Cost of SOC foot care with callus (per } \\
\text { quarter) }\end{array}$ & US $\$ 233 \cdot 51(\mathrm{US} \$ 198 \cdot 49, \mathrm{US} \$ 268 \cdot 54)$ & {$[23][24]$} & \\
\hline Cost of wound care (per month) & US $\$ 2,978 \cdot 98(\mathrm{US} \$ 2,532 \cdot 13, \mathrm{US} \$ 3,425 \cdot 83)$ & {$[25][26][27]$} & \\
\hline Cost of amputation event & US\$64,347·00 (US\$54,694·95,US\$73,999·05) & [28] & \\
\hline $\begin{array}{l}\text { Average time to wound resolution } \\
\text { (months) }\end{array}$ & $13 \cdot 2(11 \cdot 22,15 \cdot 18)$ & {$[27]$} & \\
\hline Likelihood of amputation & $0 \cdot 044(0 \cdot 037,0 \cdot 051)$ & [29] & \\
\hline \multicolumn{4}{|l|}{ Long-Term } \\
\hline SurroSense & $\operatorname{Rx}{ }^{\circledR}+$ SOC (Active Group) & & \\
\hline P5 & Likelihood that ulcer develops within 3 months (SurroSense $\mathrm{Rx}^{\circledR}+$ SOC) & $0 \cdot 067(0 \cdot 056,0 \cdot 077)$ & $\dagger$ \\
\hline P6 & $\begin{array}{l}\text { Likelihood that callus, but not ulcer, develops within } 3 \text { months (SurroSense } \\
\mathrm{Rx}^{\circledR}+\mathrm{SOC} \text { ) }\end{array}$ & $0(0,0 \cdot 015)$ & $\dagger$ \\
\hline 1-P5-P6 & $\begin{array}{l}\text { Likelihood that neither callus nor ulcer develops within } 3 \text { months (SurroSense } \\
\left.\mathrm{Rx}^{\mathbb{B}}+\mathrm{SOC}\right)\end{array}$ & $\begin{array}{l}0.933 \text { (Varies with P1 or P2; not } \\
\text { exploredseparately) }\end{array}$ & 0 \\
\hline P7 & $\begin{array}{l}\text { Likelihood that ulcer develops within next } 15 \text { months, given calluswas present } \\
\text { at } 3 \text { months }\end{array}$ & $0 \cdot 84(0 \cdot 714,0 \cdot 966)$ & \\
\hline 1-P7 & $\begin{array}{l}\text { Likelihood that ulcer does not develop within next } 15 \text { months, givencallus was } \\
\text { present at } 3 \text { months }\end{array}$ & $\begin{array}{l}0 \cdot 16 \text { (Varies with } \mathrm{P} 3 \text {; not explored } \\
\text { separately) }\end{array}$ & \\
\hline P8 & $\begin{array}{l}\text { Likelihood that ulcer develops within next } 15 \text { months, given neithercallus nor } \\
\text { ulcer was present at } 3 \text { months }\end{array}$ & $0.08(0.068,0.092)$ & \\
\hline 1-P8 & $\begin{array}{l}\text { Likelihood that ulcer does not develop within next } 15 \text { months, givenneither } \\
\text { callus nor ulcer was present at } 3 \text { months }\end{array}$ & $\begin{array}{l}0 \cdot 92 \text { (Varies with P8; not explored } \\
\text { separately) }\end{array}$ & \\
\hline \multicolumn{4}{|l|}{ SOC Only (Control Group) } \\
\hline P9 & Likelihood that ulcer develops within 3 months (SOC only) & $0 \cdot 143(0 \cdot 0122,0 \cdot 164)$ & $\dagger$ \\
\hline $\mathrm{P} 10$ & Likelihood that callus, but not ulcer, develops within 3 months (SOConly) & $0 \cdot 286(0 \cdot 243,0 \cdot 329)$ & $\dagger$ \\
\hline 1-P9-P10 & Likelihood that neither callus nor ulcer develops within 3 months (SOConly) & $\begin{array}{l}0 \cdot 571 \text { (Varies with P9 or P10; not } \\
\text { exploredseparately) }\end{array}$ & 0 \\
\hline P11 & $\begin{array}{l}\text { Likelihood that ulcer develops within next } 15 \text { months, given calluswas present } \\
\text { at } 3 \text { months }\end{array}$ & $0 \cdot 84(0 \cdot 714,0 \cdot 966)$ & {$[30]$} \\
\hline 1-P11 & $\begin{array}{l}\text { Likelihood that ulcer does not develop within next } 15 \text { months, given callus was } \\
\text { present at } 3 \text { months }\end{array}$ & $\begin{array}{l}0 \cdot 16 \text { (Varies with P11; not } \\
\text { exploredseparately) }\end{array}$ & 0 \\
\hline $\mathrm{P} 12$ & $\begin{array}{l}\text { Likelihood that ulcer develops within next } 15 \text { months, given neither callus nor } \\
\text { ulcer was present at } 3 \text { months }\end{array}$ & $0 \cdot 42(0 \cdot 357,0 \cdot 483)$ & {$[14][10]$} \\
\hline $1-\mathrm{P} 12$ & $\begin{array}{l}\text { Likelihood that ulcer does not develop within next } 15 \text { months, givenneither } \\
\text { callus nor ulcer was present at } 3 \text { months }\end{array}$ & $\begin{array}{l}0 \cdot 58 \text { (Varies with P12; not } \\
\text { exploredseparately) }\end{array}$ & 0 \\
\hline \multicolumn{4}{|l|}{ Costs } \\
\hline Cost of SOC foot care (per quarter) & 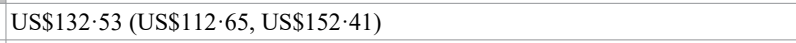 & & [23] \\
\hline $\begin{array}{l}\text { Cost of SOC foot care with callus (per } \\
\text { quarter) }\end{array}$ & US $\$ 233 \cdot 51(\mathrm{US} \$ 198 \cdot 49, \mathrm{US} \$ 268 \cdot 54)$ & & {$[23][24]$} \\
\hline Cost of wound care (per month) & US $\$ 2,978 \cdot 98(\mathrm{US} \$ 2,532 \cdot 13, \mathrm{US} \$ 3,425 \cdot 83)$ & & {$[26][27][25]$} \\
\hline Cost of amputation event & US\$64,347·00 (US\$54,694·95,US\$73,999·05) & & {$[28]$} \\
\hline $\begin{array}{l}\text { Average time to wound resolution } \\
\text { (months) }\end{array}$ & $13 \cdot 2(11 \cdot 22,15 \cdot 18)$ & & {$[27]$} \\
\hline Likelihood of amputation & $0 \cdot 044(0 \cdot 037,0 \cdot 051)$ & & [29] \\
\hline
\end{tabular}

$\dagger$ Denotes data derived from Najafi et al. [20] 
exist for patients who did not develop callus or a DFU within that first three-month window. A parallel model was developed to track longerterm outcomes (at 18 months, following closure of a previous DFU [time point 0 ]), as outlined in figure 3 .

\section{The Intervention}

This study examined the cost of SOC for management of high-risk diabetic foot patients, with and without the use of a smart insole system, the SurroSense $\mathrm{Rx}^{\otimes}$ device. This device is designed to cue offloading of sustained pressure in high-risk patients with diabetic foot disease. The device includes two pressure-sensing shoe inserts and a smartwatch display device to which on-demand offloading alerts are wirelessly sent. This allows the user to be alerted when safe pressure and time thresholds have been exceeded. The device senses pressure at locations on the foot corresponding to bony prominences-those regions carrying the highest risk for DFU development: the first metatarsal head, the lateral metatarsal heads, the great toe, the lateral toes, the lateral foot, and the heel [31]. The device provides a means of replacing sensory feedback for users experiencing LOPS as a result of diabetic neuropathy and is guaranteed for a period of one year. Periodic sensitivity adjustments may also be required and may help to extend the lifespan of the inserts.

\section{Clinical outcome-related model inputs}

Device efficacy-related model inputs were estimated using the results of a pilot cohort study completed by the Southern Arizona Limb Salvage Alliance (SALSA) at the University of Arizona. This study quantified recidivism of plantar DFU in ambulatory patients with a recent history (within the past 12 months) of DFU. Patients were each followed for six months. Over the course of the study, all patients received SOC, including standardized New Balance 928 (New Balance, Boston MA) diabetic footwear. After a two-week wear-in period, the patients were fitted with an active SurroSense $\mathrm{Rx}^{\oplus}$ device, and then followed with the technology as outpatients for three months ("Active Period"). During this time, plantar pressure data distribution, device alert patterns, and patient compliance (hours of use per day, response to alerts) were collected on an ongoing basis; callus data and DFU recidivism was collected at the end of the three-month period, and as they occurred, respectively. At the three-month mark, the device was retrieved and the patient was followed for a subsequent three months (during which patients therefore served as their own controls; "Control Period"). Callus data and DFU recidivism was similarly collected during this period. The cost-effectiveness models define an "event" as the development of a callus or an ulcer.

\section{Cost data}

Costs associated with the SurroSense $\mathrm{Rx}^{\circ}$ were provided by the manufacturer. Standard of care in DFU prevention for DPN patients is assumed to follow clinical management guidelines for patients with or without calluses, as appropriate; costs of SOC in DFU prevention are estimated through application of 2017 national average Medicare payment rates to guideline-driven medical resource utilization assumptions. Costs of wound care are estimated from the peerreviewed literature and updated to 2017 USD using the consumer price index for healthcare services (Table 1). Calluses or ulcers developing within the study period are assumed to occur at the study mid-point (6 weeks).

\section{Results}

Event rates used to drive the model are illustrated in table 2. These were observed during the active and control periods of the SALSA study. Costs associated with the model (expected costs, costs per event avoided and cost savings per additional event avoided) are also depicted in Table 2. Table 2 illustrates that in the short-term, patients managed using SurroSense $\mathrm{Rx}^{\otimes}$ in addition to SOC are expected to incur costs that are more than 1.8 times lower than those incurred by patients managed using SOC alone (device costs excluded). In addition to this, patients treated with SOC alone were approximately six times more likely to experience an event occurrence during the study period. The resultant incremental cost-effectiveness ratio (ICER) shows that the use of SurroSense $\mathrm{Rx}^{\star}$ in addition to SOC results in cost savings of US\$978.02 per each additional event avoided over the short-term; this value suggests that further investigation of the device is warranted with respect to its cost-effectiveness.

The 18-month model produced results as outlined in Table 2. These longer-term results show that the dominant DFU prevention strategy is SOC + SurroSense $\mathrm{Rx}^{\oplus}$, which results in lower ulcer occurrence rates $(0 \cdot 14$ versus 0.62$)$, as well as lower overall expected costs of care $(\$ 5,753$ versus $\$ 20,029)$ than the use of SOC alone. In this case, costs per event avoided decrease from US $\$ 53,134.94$ to US $\$ 6,702.54$ with the adjunctive use of the SurroSense $\mathrm{Rx}^{\oplus}$.

The one-way sensitivity analyses performed demonstrate that the nature of this finding is robust to all reasonable variations in modeled parameters. Specifically, for all sensitivity analyses conducted, the use of SurroSense $\mathrm{Rx}^{\oplus}$ in addition to SOC as compared to SOC alone proved to be the dominant strategy, resulting in improved outcomes while reducing the cost of care (excluding the cost of the device). The adoption of the device remains cost neutral or better when the cost of the device is less than US\$14,275.50.

Table 2. Short- (Three Months) and Long- (Eighteen Months) Term Cost-Effectiveness

\begin{tabular}{|c|c|c|c|c|c|}
\hline DFU Prevention Strategy & Expected Costs & $\begin{array}{l}\text { Rate of Event (Ulcer or } \\
\text { Callus) Occurrence }\end{array}$ & $\begin{array}{c}\text { Relative Risk(Confidence } \\
\text { Interval) }\end{array}$ & Cost per EventAvoided & $\begin{array}{l}\text { Savings per Additional } \\
\text { Event Avoided (ICER) }\end{array}$ \\
\hline \multicolumn{6}{|l|}{ Three Months } \\
\hline SOC & $\$ 785.96$ & $0 \cdot 43$ & - & $\$ 1,376 \cdot 47$ & NA \\
\hline SOC + SurroSenseRx ${ }^{\circledR} *$ & $\$ 431 \cdot 92$ & 0.07 & $0 \cdot 1556(0 \cdot 0213-1 \cdot 1355)$ & $\$ 462.94$ & $\$ 978 \cdot 02$ \\
\hline \multicolumn{6}{|l|}{ Eighteen Months } \\
\hline SOC & $\$ 20,028 \cdot 69$ & $0 \cdot 62$ & & $\$ 53,134 \cdot 94$ & NA \\
\hline SOC + SurroSense Rx ${ }^{\circledR} *$ & $\$ 5,753 \cdot 19$ & $0 \cdot 14$ & & $\$ 6,702 \cdot 54$ & DOMINANT \\
\hline
\end{tabular}

* Costs do not include the cost of the SurroSense Rx ${ }^{\circledR}$ device 


\section{Discussion}

Table 2 presents the short- (three months) and long- (eighteen months) term cost-effectiveness results with respect to being treated with either SOC alone or with the SurroSense $\mathrm{Rx}^{\circ}$ as an adjunct to the SOC. The short-term results illustrate immediate decreases in costs (device costs not included)- expected costs (\$431.92), costs per event avoided (\$462.94), and savings per additional event avoided (\$978.02)which parallels the decrease in the rate of event occurrence to approximately one-sixth of the event rate for SOC alone. These initial short-term results suggest that the use of the SurroSense $\mathrm{Rx}^{\infty}$ is likely to be cost-effective. Sensitivity analyses performed suggest that this holds robustly for variations in the modeled parameters, with the use of SurroSense $\mathrm{Rx}^{\oplus}$ in addition to SOC, as compared to SOC alone, proving to be the dominant strategy, thus resulting in improved outcomes while reducing the cost of care (excluding the cost of the device). That is, based on the data collected, the adoption of the device as an adjunct for the prevention of DFU recidivism remains cost neutral or better when the cost of the device is less than US\$14,275.50. Long-term and larger scale results are required to verify this early, but very promising, finding.

The long-term results illustrate a stronger cost-savings pattern in that expected costs decrease from $\$ 20,028.69$ to $\$ 5,753.19$ and costs per ulcer avoided decrease from $\$ 53,134.94$ to $\$ 6,702.54$ when the SurroSense $\mathrm{Rx}^{\oplus}$ is used as an adjunct to the current SOC. Along with these cost savings, table 2 illustrates that the use of the SurroSense $\mathrm{Rx}^{\oplus}$ as an adjunct to the SOC decreases the rate of event occurrence to more than one quarter $(0 \cdot 14)$ of the rate for SOC alone. The decrease in all costs and the rate of event occurrence suggests that the use of the SurroSense $\mathrm{Rx}^{\oplus}$ is cost-effective and that it should be used as an adjunct to the standard of care.

The implications of these cost savings become increasingly evident when the rate of ulcer recurrence over time is further examined. On average, ten percent of ulcers recur within three months $[10,11]$. This metric jumps to 40.3 percent at eighteen months post-ulcer healing $[10,11,14]$. The ability to use the SurroSense $\mathrm{Rx}^{\oplus}$ over three and eighteen months with the natural risk of ulceration increasing, yet be able to decrease expected costs and the cost per event avoided, reflects the potential of the SurroSense $\mathrm{Rx}^{\oplus}$ device.

In exploring the effectiveness of preventative treatment in diabetic foot care, a Markov model has been used to illustrate that reducing the incidence of ulceration and amputation by one quarter deems it to be a cost-effective method of treatment [32]. This metric is further corroborated by two publications which indicate cost effectiveness at the point which ulceration and amputation have decreased from 25$40 \%[33,34]$. The SurroSense $\mathrm{Rx}^{\otimes}$ device far exceeds these measures in both the short- and long-term. In the short-term, the adjunctive use of the SurroSense $\mathrm{Rx}^{\oplus}$ resulted in the rate of event occurrence changing from 0.43 to 0.07 , an $83.72 \%$ decrease. In the long-term, the adjunctive use of the SurroSense $\mathrm{Rx}^{\oplus}$ resulted in the rate of event occurrence changing from 0.62 to $0 \cdot 14$, a $77.42 \%$ decrease.

There are no directly comparable means of preventative care that exist as a treatment for diabetic foot ulcers; however, there are other existing actions being taken in order to reduce the incidence of ulcer recurrence. An example of this includes customized footwear and improved methods of offloading in this footwear. Studies have shown that improved offloading in customized footwear can reduce plantar ulcer recurrence; however, not by a significant amount [14]. This finding can be due to the intervention itself and the lack of compliance typically observed in this patient population [14]. With an insignificant ability to reduce the incidence of ulcer recurrence, further research, such as that taking place with the SurroSense $\mathrm{Rx}^{\circledR}$, is encouraged.

Our previous studies have demonstrated that the SurroSense $\mathrm{Rx}^{\circ}$ device is perceived to be effective and acceptable by high-risk foot patients, and could enhance adherence to prescribed footwear [20]. This study suggests that the use of this device carries significant promise as it provides patients with a cost-effective adjunct to the standard of care in an effort to prevent recurrent DFUs.

It should be noted that the short-term results are a significant underestimation of long-term costs associated with managing DFUs. In reality, the average cost of DFU treatment is approximately $\$ 40,000$. Additionally, in approximately $4.4 \%$ of cases, non-healing DFUs result in amputation with an expected event cost of an additional $\$ 64,000[28,29]$.

In order to monitor the long-term implications of using the SurroSense $\mathrm{Rx}^{\oplus}$ device, it is necessary to expand the observation of SurroSense $\mathrm{Rx}^{\oplus}$ users beyond the short window examined with the SALSA-Orpyx study. The most prevalent ulcer recurrence period is six to 12 months after the previous ulcer has healed. The findings of Galea et al. validate this time period as their results show that $53 \cdot 1 \%$ and $59.4 \%$ of ulcers recur within six and 12 months, respectively [12]. This time frame suggests that conducting research which extends beyond six months of monitoring for ulcer recurrence is imperative in drawing definitive conclusions regarding the efficacy of the SurroSense $\mathrm{Rx}^{\oplus}$ device and its economic implications. Longer term, multi-site randomized controlled trials are required to validate the findings of the SALSA-Orpyx cohort study. With conclusive outcome and probability data regarding use of the device as an adjunct in diabetic foot care, broader health system and societal impacts regarding use of such an intervention can be confidently drawn.

\section{Conclusions}

When used as an adjunct to the current standard of care, the SurroSense $\mathrm{Rx}^{\otimes}$ device is a cost-effective means of preventing DFU recidivism with a long-term cost per event avoided of under US $\$ 7,000$, resulting in an overall cost of care that is over $70 \%$ lower than current expected cost of care with standard of care alone. With foot ulcer care comprising a large portion of the direct cost of care of diabetes, this device shows early promise in cost effectively managing patients at a high-risk of diabetic foot complications.

\section{Funding sources} Inc.

All Financial Support was provided by Orpyx Medical Technologies

\section{Acknowledgements}

Author contributions: All authors contributed to this manuscript.

Drs Najafi, Razjouyan and Armstrong were involved in the collection of the clinical data, and the statistical analysis thereof, that was used for the model. These authors take responsibility for the integrity of the data and its collection.

Dr. Brooks developed the cost-effectiveness models in this manuscript and takes responsibility for the integrity of their functionality.

Dr. Everett and Ms. Chalifoux completed the background literature review and they prepared the majority of the prose for the article. 
Author access to data: All authors were provided with access to clinical input data and the models required to write this manuscript.

\section{Conflict of interest disclosures}

Dr. Breanne Everett is a co-founder of, and serves as the CEO for, Orpyx Medical Technologies Inc. Ms. Courtney Chalifoux serves as the company's Clinical Trials and Regulatory Affairs Manager.

\section{Role of the sponsor}

The sponsor was not involved in collecting the data used to run the economic model. They were also not involved in the construction of the economic model itself.

\section{Compensation of non-authoring parties}

As all contributing parties are authors on this manuscript, no further compensation was required.

\section{References}

1. David J Margolis, D Scot Malay, Ole J Hoffstad MA, Charles E Leonard, Thomas MaCurdy, et al. (2011) Incidence of diabetic foot ulcer and lower extremity amputation among Medicare beneficiaries, 2006 to 2008. Data Points Publication Series [Crossref]

2. Armstrong DG, Boulton AJM, Bus SA (2017) Diabetic Foot Ulcers and their Recurrence. N Engl J Med 376: 2367-2375. [Crossref]

3. Amlung SR, Miller WL, Bosley LM (2001) The 1999 National Pressure Ulcer Prevalence Survey: a benchmarking approach. Adv Skin Wound Care 14: 297-301. [Crossref]

4. Reiber GE, Vileikyte L, Boyko EJ, del Aguila M, Smith DG, et al. (1999) Causal pathways for incident lower-extremity ulcers in patients with diabetes from two settings. Diabetes Care 22: 157-162. [Crossref]

5. Young MJ, Breddy JL, Veves A, Boulton AJ (1994) The prediction of diabetic neuropathic foot ulceration using vibration perception thresholds. A prospective study. Diabetes Care 17: 557-560. [Crossref]

6. Reiber GE, Ledoux WR (2002) Epidemiology of Diabetic Foot Ulcers and Amputations: Evidence for Prevention. The Evidence Base for Diabetes Care, John Wiley \& Sons, Ltd: 641-665.

7. Singh N, Armstrong DG, Lipsky BA (2005) Preventing foot ulcers in patients with diabetes. JAMA 293: 217-228. [Crossref]

8. Monteiro-Soares M, Boyko EJ, Ribeiro J, Ribeiro I, Dinis-Ribeiro M (2012) Predictive factors for diabetic foot ulceration: a systematic review. Diabetes Metab Res Rev 28: 574-600. [Crossref]

9. Crawford F, Cezard G, Chappell FM, Murray GD, Price JF, Sheikh A, et al. (2015) A systematic review and individual patient data meta-analysis of prognostic factors for foot ulceration in people with diabetes: the international research collaboration for the prediction of diabetic foot ulcerations (PODUS). Health Technol Assess 19: 1-210 [Crossref]

10. Waaijman R, de Haart M, Arts MLJ, Wever D, Verlouw AJ, et al. (2014) Risk factors for plantar foot ulcer recurrence in neuropathic diabetic patients. Diabetes Care 37: 1697-1705. [Crossref]

11. Apelqvist J, Larsson J, Agardh CD (1993) Long-term prognosis for diabetic patients with foot ulcers. J Intern Med 233: 485-491. [Crossref]

12. Galea AM, Springett K, Bungay H, Clift S, Fava S, Cachia M (2009) Incidence and location of diabetic foot ulcer recurrence. Diabetic Foot Ulcer 12:181-189.

13. Nhan L, Strauss M, Miller S (2013) Risk factors for diabetic foot ulcers: the first step in prevention. Consultant 53: 800-803.

14. Bus SA, Waaijman R, Arts M, de Haart M, Busch-Westbroek T, van Baal J, et al. (2013) Effect of custom-made footwear on foot ulcer recurrence in diabetes: a multicenter randomized controlled trial. Diabetes Care 36: 4109-4116. [Crossref]
15. Uccioli L, Faglia E, Monticone G, Favales F, Durola L, et al. (1995) Manufactured shoes in the prevention of diabetic foot ulcers. Diabetes Care 18: 1376-1378. [Crossref]

16. Busch K, Chantelau E (2003) Effectiveness of a new brand of stock "diabetic" shoes to protect against diabetic foot ulcer relapse. A prospective cohort study. Diabet Med 20: 665-669. [Crossref]

17. Armstrong DG, Holtz-Neiderer K, Wendel C, Mohler MJ, Kimbriel HR, et al. (2007) Skin temperature monitoring reduces the risk for diabetic foot ulceration in high-risk patients. Am J Med 120: 1042-1046. [Crossref]

18. Matricali GA, Deroo K, Dereymaeker G (2003) Outcome and recurrence rate of diabetic foot ulcers treated by a total contact cast: short-term follow-up. Foot Ankle Int 24: 680-684.

19. Skrepnek GH, Mills JL Sr, Lavery LA, Armstrong DG (2017) Health Care Service and Outcomes Among an Estimated 6.7 Million Ambulatory Care Diabetic Foot Cases in the U.S. Diabetes Care 40: 936-942. [Crossref]

20. Najafi B, Ron E, Enriquez A, Marin I, Razjouyan J et al. (2017) Smarter Sole Survival Will Neuropathic Patients at high-risk for Ulceration Use a Smart Insole-Based Foot Protection System? J Diabetes Sci Technol 11: 702-713. [Crossref]

21. Hatch DC, Armstrong DG (2016) Innovations in the management of DFUs and the diabetic foot in remission. World Union of Wound Healing Societies Position Document on Local Management of Diabetic Foot Ulcers.

22. Bus SA, Armstrong DG, van Deursen RW, Lewis JEA, Caravaggi CF, et al. (2016) IWGDF guidance on footwear and offloading interventions to prevent and heal foot ulcers in patients with diabetes. Diabetes Metab Res Rev 32: 25-36. [Crossref]

23. Hingorani A, LaMuraglia GM, Henke P, Meissner MH, Loretz L, et al. (2016) The management of diabetic foot: A clinical practice guideline by the Society for Vascular Surgery in collaboration with the American Podiatric Medical Association and the Society for Vascular Medicine. J Vasc Surg; 63: 3S-21S. [Crossref]

24. Arosi I, Hiner G, Rajbhandari S (2016) Pathogenesis and Treatment of Callus in the Diabetic Foot. Curr Diabetes Rev 12:179-183. [Crossref]

25. Ramsey SD, Newton K, Blough D, McCulloch DK, Sandhu N, et al. (1999) Incidence, outcomes, and cost of foot ulcers in patients with diabetes. Diabetes Care 22: 382-387. [Crossref]

26. Gordois A, Scuffham P, Shearer A, Oglesby A, Tobian JA (2003) The health care costs of diabetic peripheral neuropathy in the US. Diabetes Care 26: 1790-1795. [Crossref]

27. Shearer A, Scuffham P, Gordois A, Oglesby A (2003) Predicted costs and outcomes from reduced vibration detection in people with diabetes in the U.S. Diabetes Care 26 2305-2310. [Crossref]

28. Franklin H, Rajan M, Tseng C-L, Pogach L, Sinha A, et al. (2014) Cost of lower-limb amputation in U.S. veterans with diabetes using health services data in fiscal years 2004 and 2010. J Rehabil Res Dev 51: 1325-1330. [Crossref]

29. Rice JB, Desai U, Cummings AKG, Birnbaum HG, Skornicki M, et al. (2014) Burden of diabetic foot ulcers for medicare and private insurers. Diabetes Care 37: 651-658. [Crossref]

30. Murray HJ, Young MJ, Hollis S, Boulton AJ (1996) The association between callus formation, high pressures and neuropathy in diabetic foot ulceration. Diabet Med 13: 979-982. [Crossref]

31. Rogers LC, Lavery LA, Armstrong DG (2008) The right to bear legs--an amendment to healthcare: how preventing amputations can save billions for the US Health-care System. J Am Podiatr Med Assoc 98: 166-168. [Crossref]

32. Boulton AJM, Vileikyte L, Ragnarson-Tennvall G, Apelqvist J (2005) The global burden of diabetic foot disease. Lancet 12: 1719-1724. [Crossref]

33. Ortegon MM, Redekop WK, Niessen LW (2004) Cost-Effectiveness of Prevention and Treatment of the Diabetic Foot. Diabetes Care 27: 901-907. [Crossref]

34. Rauner MS, Heidenberger K, Pesendorfer EM (2004) Using a Markov model to evaluate the cost-effectiveness of diabetic foot prevention strategies in Austria. Proceedings of the Western Multiconference, International Conference on Health Sciences Simulation, 63-68.

Copyright: (C2018 Najafi B. This is an open-access article distributed under the terms of the Creative Commons Attribution License, which permits unrestricted use, distribution, and reproduction in any medium, provided the original author and source are credited. 